Article

\title{
Combining FY-3D MWTS-2 with AMSU-A Data for Inter-Decadal Diurnal Correction and Climate Trends of Atmospheric Temperature
}

\author{
Xinlu Xia (D) and Xiaolei Zou * \\ Center of Data Assimilation for Research and Application, Nanjing University of Information Science \& \\ Technology, Nanjing 210044, China; stephenxia@nuist.edu.cn \\ * Correspondence: xzou@nuist.edu.cn
}

check for updates

Citation: Xia, X.; Zou, X. Combining FY-3D MWTS-2 with AMSU-A Data for Inter-Decadal Diurnal Correction and Climate Trends of Atmospheric Temperature. Remote Sens. 2021, 13, 3148. https://doi.org/10.3390/ rs13163148

Academic Editor: Seon Ki Park

Received: 14 July 2021

Accepted: 6 August 2021

Published: 9 August 2021

Publisher's Note: MDPI stays neutral with regard to jurisdictional claims in published maps and institutional affiliations.

Copyright: (c) 2021 by the authors. Licensee MDPI, Basel, Switzerland. This article is an open access article distributed under the terms and conditions of the Creative Commons Attribution (CC BY) license (https:/ creativecommons.org/licenses/by/ $4.0 /$ )

\begin{abstract}
Microwave temperature sounding observations from polar-orbiting meteorological satellites have been widely used for research on climate trends of atmospheric temperature at different heights around the world. Taking the Amazon rainforest as the target area, this study combined the Microwave Temperature Sounder-2 (MWTS-2) data onboard the Chinese FengYun-3D (FY-3D) satellite with the Advanced Microwave Sounding unit-A (AMSU-A) data onboard the National Oceanic and Atmospheric Administration (NOAA) and the European Meteorological Operational (MetOp) polar-orbiting meteorological satellites (i.e., NOAA-15, -18, -19, MetOp-A, -B). The double difference method was used to estimate and thus eliminate the inter-sensor bias, and a decadal diurnal correction was used to reduce the impact of different local equator crossing times on climate trends. The "no-rain" conditions were determined for AMSU-A data by channels 1 and 15, and for MWTS-2 data by channels 1 and 7. Finally, the decadal linear trends of atmospheric temperature from 1998 to 2020 were obtained after applying the inter-sensor bias calibration and inter-decadal diurnal correction to AMSU-A and MWTS-2 data from NOAA-15, -18, -19; MetOp-A, -B; and FY-3D. A warming trend was found in the AMSU-A window and tropospheric channels (1-9 and 15 ) and a cooling trend in stratospheric channels (10-14). The warming (cooling) trends of channels 7-9 (10) were relatively small. The warming (cooling) trends of AMSU-A channels 1-6 (14-15) were significantly reduced after the inter-decadal diurnal correction.
\end{abstract}

Keywords: MWTS-2; inter-decadal diurnal correction; warming trend

\section{Introduction}

The Chinese third generation polar-orbiting meteorological satellite Feng Yun-3D (FY-3D) was launched in November 2017. It carries the Microwave Temperature Sounder-2 (MWTS-2), which has 13 channels with central frequencies ranging from $50.3 \mathrm{GHz}$ to 57.6 GHz that are designed for observing the atmospheric temperature profiles from the Earth's surface to the lower stratosphere. Except for lacking two window channels, the FY-3D MWTS-2 is similar to the Advanced Microwave Sounding Unit-A (AMSU-A) onboard the National Oceanic and Atmospheric Administration (NOAA) and the European Meteorological Operational (MetOp) satellites. The central frequencies of MWTS-2 channels 1 and 3-13 are the same as those of AMSU-A channels 3-14. The center frequency of MWTS-2 channel 2 is located at $51.76 \mathrm{GHz}$ and has no corresponding AMSU-A channel. Compared with surface station measurements [1], ship measurements [2] and radiosonde measurements [3], satellite observations have global coverage that is advantageous for many investigations of the atmosphere. Satellite microwave data have not only been widely used in numerical weather prediction [4-6] but also in global climate change studies [7-9].

A large number of studies have been done on the applications of MWTS-2 and AMSUA observations. [10] proposed a limb correction method to remove scan-dependent features of MWTS-2 so that the underlying weather signals can be uncovered. Ref. [11] developed a 
clear-sky data selection algorithm based on the differences of MWTS- 2 channel-1 brightness temperature between observations and model simulations. Ref. [12] described and evaluated limb adjustment procedures in the AMSU-A with a combined physical and statistical technique. Ref. [13] monitored and estimated the maximum sustained wind speeds of Atlantic tropical cyclones with information on the strength of the middle and upper tropospheric warm cores provided by AMSU-A data. Ref. [14] used a single Microwave Sounding Unit (MSU) channel 2 to detect global warming in the lower troposphere, ranging from $0.08 \mathrm{~K}$ to $0.22 \mathrm{~K}$ per decade. The University of Alabama Huntsville (UAH), Remote Sensing system (RSS) and NOAA Center for Satellite Applications and Research have developed up-to-date, homogeneous datasets of mid-tropospheric temperature based on AMSU-A data [15-17].

Because of the limited life spans of polar-orbiting meteorological satellites, the length of data provided by a single satellite is often not long enough to support climate research. It is thus necessary to merge data from different satellites. This study combined FY-3D MWTS-2 data with AMSU-A data from NOAA-15, -18, -19 and MetOp-A, -B to demonstrate its added value to diurnal correction and to derive the climate trend of atmospheric temperature from the surface to the lower stratosphere. Since satellite microwave data are obtained by two-point calibration formula, there is an inter-sensor bias between data obtained by different microwave sounders [18]. Only after a bias correction can the microwave data from different satellites be combined for obtaining the climate trend. Besides the inter-satellite bias removal, a diurnal correction is also needed due to differences of equator-crossing times among different polar-orbiting meteorological satellites. Ref. [19] adopted a method based on a climate model to estimate the effects of diurnal correction on the diurnal variation in MSU observations. Ref. [20] described the diurnal variation of AMSU-A brightness temperature observations in the Amazon area in July, August, and October 2002. Ref. [21] analyzed the diurnal variation characteristics of AMSU-A brightness temperature of climatology in the Amazon and evaluated the impact of diurnal variation correction on linear climate trend. Based on [21], we added FY-3D MWTS-2 data to further analyze the inter-decadal diurnal variation of brightness temperature in the Amazon area, and we applied this inter-decadal variation to diurnal correction for linear climate trends.

In this study, the Amazon rainforest was selected as the study area $\left(1^{\circ} \mathrm{S}-4^{\circ} \mathrm{N}, 53^{\circ} \mathrm{W}-\right.$ $59^{\circ} \mathrm{W}$ ). It is one of the largest homogeneous land areas in the world, which is covered by dense vegetation. Therefore, only the radiation from the canopy and atmosphere needs to be taken into account, and the brightness temperatures observed by satellite are more stable than elsewhere where the surface emissivity varies greatly [20]. The main goal of this study was to combine FY-3D MWTS-2 with AMSU-A data for estimating climate trends of atmospheric temperature by applying an inter-sensor calibration and an inter-decadal diurnal correction. The remaining parts of the article are organized as follows. Section 2 describes the channel characteristics of MWTS-2 and AMSU-A, the method of the intersensor calibration, and the determination of "no-rain" MWTS-2 data and diurnal correction. The results of inter-sensor calibration and inter-decadal diurnal variations, and the impacts of inter-sensor calibration and inter-decadal diurnal correction on linear climate trends, are shown in Section 3. Section 4 presents a summary and conclusions.

\section{Data and Methods}

\subsection{Channel Characteristics of MWTS-2 and AMSU-A}

MWTS-2 is a cross-track microwave sounder with 13 channels, whose weighting functions (WFs) distribute from near the Earth's surface to the lower stratosphere. The first MWTS-2 was carried on the FY-3C satellite that was launched in 2013 but became out of operation in 2015. The FY-3D MWTS-2 data are used in this study. The swath width of MWTS-2 is $2600 \mathrm{~km}$ with 90 fields of view (FOVs) along each scan line. The spatial resolution of MWTS-2 FOV is about $30 \mathrm{~km}$ at nadir. MWTS-2 is similar to AMSU-A, which is a cross-track microwave sounder with 15 channels, which can observe atmospheric 
temperature from the surface to the lower stratosphere. The first AMSU-A was carried on the NOAA-15 satellite launched by America in 1998. Its swath width is $2300 \mathrm{~km}$ with 30 FOVs along each scan line. The spatial resolution of AMSU-A FOV is about $50 \mathrm{~km}$ at nadir. The AMSU-A has three more window channels (channels 1, 2, and 15), which are missing for MWTS-2. More details of channel characteristics of MWTS-2 and AMSU-A are shown in Table 1.

Table 1. Channel number, center frequency (GHz), noise equivalent differential temperature (NEDT, unit: K), and weighting function peak level (WFPL, unit: $\mathrm{hPa}$ ) of AMSU-A and MWTS-2. Horizontal $(\mathrm{H})$ or vertical $(\mathrm{V})$ polarization is indicated in brackets.

\begin{tabular}{ccccccc}
\hline \multicolumn{1}{c}{ Channel Number } & \multicolumn{2}{c}{ Frequency } & \multicolumn{2}{c}{ NEDT } & WFPL \\
\hline AMSU-A & MWTS-2 & AMSU-A & MWTS-2 & AMSU-A & MWTS-2 \\
\hline 1 & - & $23.80(\mathrm{~V})$ & - & 0.30 & - & 1085 \\
\hline 2 & - & $31.40(\mathrm{~V})$ & - & 0.30 & - & 1085 \\
\hline 3 & 1 & $50.30(\mathrm{~V})$ & $50.30(\mathrm{H})$ & 0.40 & 1.20 & 950 \\
\hline- & 2 & - & $51.76(\mathrm{H})$ & - & 0.75 & 950 \\
\hline 4 & 3 & $52.80(\mathrm{~V})$ & $52.80(\mathrm{H})$ & 0.25 & 0.75 & 850 \\
\hline 5 & 4 & $53.596(\mathrm{H})$ & 0.25 & 0.75 & 700 \\
\hline 6 & 5 & $54.400(\mathrm{H})$ & 0.25 & 0.75 & 400 \\
\hline 7 & 6 & $54.94(\mathrm{~V})$ & $54.94(\mathrm{H})$ & 0.25 & 0.75 & 250 \\
\hline 8 & 7 & $55.500(\mathrm{H})$ & 0.25 & 0.75 & 200 \\
\hline 9 & 8 & $\mathrm{f}_{0}(\mathrm{H})=57.29 \mathrm{GHz}$ & 0.25 & 0.75 & 100 \\
\hline 10 & 9 & $\mathrm{f}_{0} \pm 0.217(\mathrm{H})$ & 0.40 & 1.20 & 50 \\
\hline 11 & 10 & $\mathrm{f}_{0} \pm 0.322 \pm 0.048(\mathrm{H})$ & 0.40 & 1.20 & 25 \\
\hline 12 & 11 & $\mathrm{f}_{0} \pm 0.322 \pm 0.022(\mathrm{H})$ & 0.60 & 1.70 & 10 \\
\hline 13 & 12 & $\mathrm{f}_{0} \pm 0.322 \pm 0.010(\mathrm{H})$ & 0.80 & 2.40 & 5 \\
\hline 14 & 13 & $\mathrm{f}_{0} \pm 0.322 \pm 0.005(\mathrm{H})$ & 1.20 & 3.60 & 2 \\
\hline 15 & - & $89(\mathrm{~V})$ & 0.05 & - & 1085 \\
\hline
\end{tabular}

The microwave data used in this study were level-1B nadir observations of brightness temperature from FY-3D, NOAA-15, -18, -19, and MetOp-A, -B. Table 2 shows the time period of data from each satellite and the dates of those failed channels. Data since the failing dates were not used in the study.

Table 2. Time periods of microwave data used in this study from different satellites and their failed time.

\begin{tabular}{ccc}
\hline Satellite & Start Date (Year-Month-Day) & End Date (Year-Month-Day) \\
\hline NOAA-15 & $1998-10-26$ & $2020-12-31$ \\
\hline NOAA-18 & $2005-05-24$ & $2020-12-31$ \\
\hline NOAA-19 & $2009-02-06$ & $2020-12-31$ \\
\hline MetOp-A & $2007-01-01$ & $2020-12-31$ \\
\hline MetOp-B & $2012-09-24$ & $2020-12-31$ \\
\hline FY-3D & $2019-01-01$ & $2020-12-31$ \\
\hline Satellite & Channel & Failure date (year-month) \\
\hline
\end{tabular}


Table 2. Cont.

\begin{tabular}{ccc}
\hline Satellite & Start Date (Year-Month-Day) & End Date (Year-Month-Day) \\
\cline { 2 - 3 } & 6 & $2004-01$ \\
\cline { 2 - 3 } NOAA-15 & 11 & $2002-04$ \\
\hline NOAA-19 & 14 & $2000-10$ \\
\hline \multirow{2}{*}{ MetOp-A } & 8 & $2009-12$ \\
\hline MetOp-B & 7 & $2009-12$ \\
\hline & 8 & $2015-09$ \\
\hline
\end{tabular}

\subsection{The DD Method for Inter-Sensor Calibration}

To calibrate the inter-sensor bias, we first used the Simultaneous Nadir Overpass (SNO) method [22] to find their observations at the same place and time, and then we used the Double Difference (DD) method [23] to calculate and eliminate the inter-satellite bias. Figure 1 shows the monthly mean local equator-crossing times (LECT) of seven satellites that were in orbit from 1998 to 2020. It shows that orbital drift happened to most satellites. The data length from FY-3C was too short, so it will not be used in this study. All 15 channels of AMSU-A onboard NOAA-18 were in normal operation since its launch in 2005. We therefore decided to use the NOAA-18 AMSU-A observations as the reference dataset for inter-sensor calibration. In order to avoid the uncertainty caused by cloud and surface emissivity, only observations over ocean under clear-sky conditions were selected for inter-sensor calibration by the DD method. For AMSU-A, clear-sky conditions were defined as liquid water path (LWP) $\leq 0.01 \mathrm{~kg} / \mathrm{m}^{2}$ [24], where the LWP can be calculated by AMSU-A channels 1 and 2 [25]. For MWTS-2 data, clear-sky conditions were obtained by channel 1 [11]. The spatio-temporal matching criteria for selecting the SNO data were as follows: (1) spatial separation less than $5 \mathrm{~km}$ and (2) a time difference less than $10 \mathrm{~min}$.

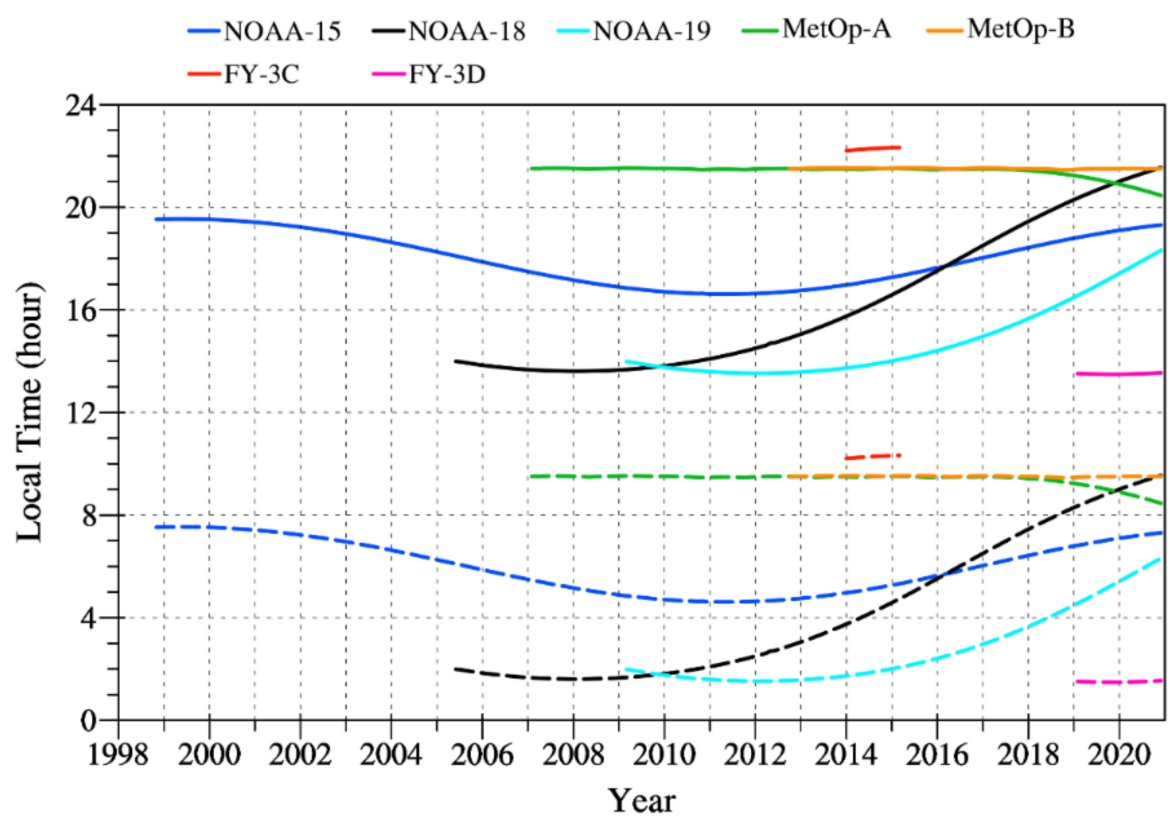

Figure 1. Monthly mean local equator-crossing times of the polar-orbiting meteorological satellites NOAA-15/18/19, MetOp-A/B, and FY-3C/3D calculated from near-nadir observations on ascending (solid curves) and descending (dashed curves) nodes from October 1998 to December 2020.

When using the DD method for inter-sensor calibration, in addition to brightness temperature observations at each SNO point, we also needed the corresponding simulated 
brightness temperature. In this study, the simulated brightness temperature were derived from the Radiative Transfer model for TOVS (RTTOV, version 12.3) developed by the European Centre for Medium-range Weather Forecasts (ECMWF) [26,27] and the ERA-5 global reanalysis as the input to RTTOV. The input variables to RTTOV mainly include the vertical profiles of the atmospheric temperature, the water vapor mixing ratio, and pressure as well as the surface variables of the surface skin temperature, humidity, and wind speed. Having obtained simulated brightness temperature $\left(B_{s a t}\right)$, the inter-sensor bias can be eliminated by the DD method. For brevity, the microwave sounder (AMSU-A and MWTS-2) observations are indicated as $\mathrm{O}$, and the RTTOV simulations are indicated as B. For a given channel:

$$
\begin{gathered}
O_{\text {sat }}=O_{\text {sat,true }}+\mu_{O_{\text {sat }}} \\
B_{\text {sat }}=B_{\text {sat }, \text { true }}+\mu_{B_{\text {sat }}}
\end{gathered}
$$

where the subscript "sat" indicates the data from one of FY-3D, NOAA-15/19, and MetOp$\mathrm{A} / \mathrm{B}, O_{\text {sat,true }}$, and $B_{\text {sat, true }}$ represent the true brightness temperatures, and $\mu_{O_{\text {sat }}}$ and $\mu_{B_{\text {sat }}}$ represent the bias of observation and simulation, respectively. Considering the following relationships:

$$
\begin{gathered}
\overline{O_{\text {sat }}-B_{\text {sat }}}=\mu_{O_{\text {sat }}}-\mu_{B_{s a t}} \\
\overline{O_{N O A A-18}-B_{N O A A-18}}=\mu_{O_{N O A A-18}}-\mu_{B_{N O A A-18}}
\end{gathered}
$$

Taking the differences of both sides between Equations (1)-(4), we obtained

$$
\overline{O_{s a t}-B_{s a t}}-\overline{O_{N O A A-18}-B_{N O A A-18}}=\left(\mu_{O_{s a t}}-\mu_{O_{N O A A-18}}\right)-\left(\mu_{B_{s a t}}-\mu_{B_{N O A A-18}}\right)
$$

Because the systematic errors of both the RTTOV model and the ERA- 5 reanalysis are stable, the long-term mean of $B_{s a t, \mu}$ for all instruments was assumed to be the same, i.e.,:

$$
\mu_{B_{\text {sat }}}-\mu_{B_{N O A A-18}}=0
$$

Equation (5) can be simplified as:

$$
\overline{O_{s a t}-B_{s a t}}-\overline{O_{N O A A-18}-B_{N O A A-18}}=\mu_{O_{s a t}}-\mu_{O_{N O A A-18}} \equiv \mu_{s a t D D}
$$

where $\mu_{\text {sat DD }}$ represents the inter-sensor bias between "sat" (FY-3D, NOAA-15/19 or MetOp-A/B) and NOAA-18.

\subsection{Determination of "No-Rain" Data}

In addition to inter-satellite bias removal, all brightness temperature data used for climate trends must meet the "no-rain" condition. Ref. [28] defined a scattering index $\left(S_{89}\right)$ using the differences of brightness temperature between AMSU-A window channels 1 and $15, S I_{89}=T_{b, c h 1}-T_{b, c h 15}$. There is a good relationship between precipitation and the scattering index being greater than $3 \mathrm{~K}$. In other words, the "no-rain" condition can be defined as $S I_{89} \leq 3 \mathrm{~K}$. Since the MWTS-2 has no window channels corresponding to AMSU-A channels 1 and 15, we proposed to use MWTS-2 channels 1 and 7 (corresponding to AMSU-A channels 3 and 8) to define the "no-rain" condition. Selecting all the NOAA18 AMSU-A nadir observations over the Amazon area from 2005 to 2020, we examined the relationships between the differences of AMSU-A brightness temperature between channels 1 and 15 and those between channels 3 and 8 (Figure 2). It can be seen that for the data when $S I_{89} \geq 3 \mathrm{~K}(<3 \mathrm{~K})$, the differences between the channels 1 and 15 (x-axis) were negatively (positively) correlated to the differences between channels 3 and 8 (y-axis). In order to find a relationship for identifying "no-rain" data using differences of brightness temperature observations between MWTS-2 channels 1 and 6, which correspond to AMSUA channels 3 and 7 (See Table 1), we first carried out a linear regression on all the data satisfying $S I_{89}<3$ to obtain the linear function. We then did a linear regression to all the data below this regression line plus $2 \mathrm{~K}$ to obtain the regression function (black solid line in 
Figure 2). We finally moved this regression line upward by 3 standard deviations to obtain the linear function (black dashed line in Figure 2). All the AMSU-A data below the blackdashed line were considered to be observations under the "no-rain" condition, which was the "no-rain" index proposed by [28]. Because MWTS-2 has no window channels shown on the y-axis in Figure 2, we approximately considered the MWTS-2 observations being under the "no-rain" condition when the differences of brightness temperature observations between MWTS- 2 channels 1 and 7 were greater than $71 \mathrm{~K}$.

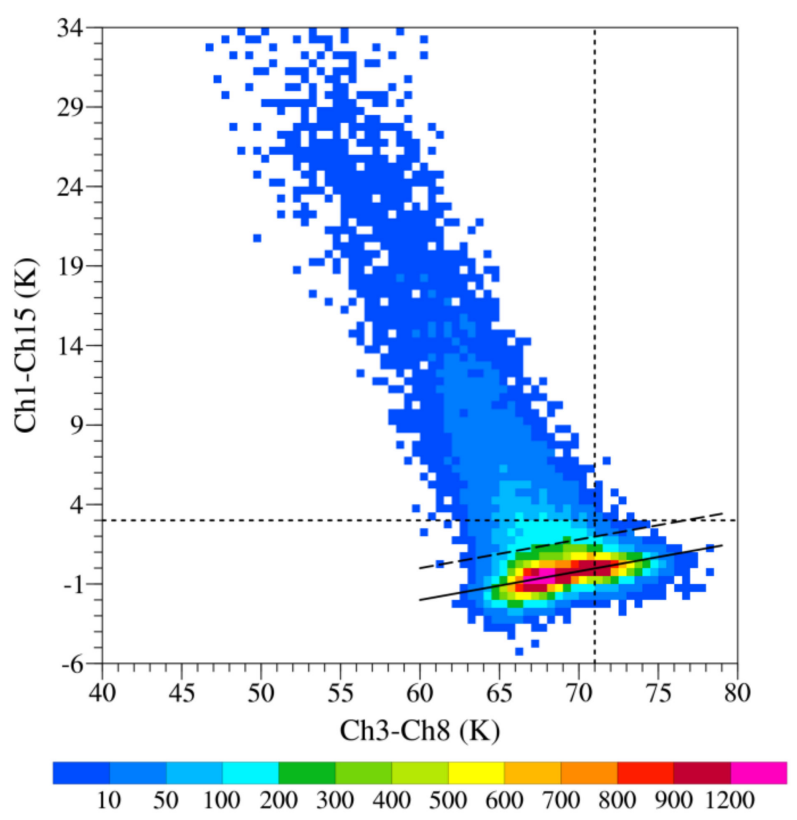

Figure 2. Data counts at $0.5-\mathrm{K}$ intervals of brightness temperature difference from NOAA-18 AMSU-A nadir observations over Amazon area $\left(1^{\circ} \mathrm{S}-4^{\circ} \mathrm{N}, 53^{\circ} \mathrm{W}-59^{\circ} \mathrm{W}\right)$ during 2005 to 2020.

\subsection{Diurnal Correction Method}

Different satellites passed over the Amazon area at different local times. A diurnal correction was therefore implemented before calculating climate trends. Ref. [20] proposed a method for estimating diurnal variation based on monthly mean observations. For each channel, the diurnal variation of brightness temperature can be expressed by the following second-order Fourier series:

$$
\begin{array}{rlc}
T_{b, d c}(t) & = & A_{0}+\sum_{n=1}^{2}\left(A_{n} \sin n \theta+B_{n} \cos n \theta\right) \\
& =A_{0}+A_{1} \sin \theta+B_{1} \cos \theta+A_{2} \sin 2 \theta+B_{2} \sin 2 \theta
\end{array}
$$

where $\theta=\frac{\pi t}{12}(0 \leq t \leq 24 \mathrm{~h})$, and $A_{0}, A_{1}, B_{1}, A_{2}$ and $B_{2}$ are unknown coefficients, which are to be calculated by multivariate linear fitting with monthly observations $\left(T_{b, o b s}(t)\right)$. When the diurnal variation is obtained, a diurnal correction can then be carried out as follows [19]:

$$
T_{b}^{c o r r}\left(t_{r e f}\right)=T_{b}^{o b s}\left(t_{o b s}\right)+\left(T_{b, d c}\left(t_{r e f}\right)-T_{b, d c}\left(t_{o b s}\right)\right)
$$

where $T_{b}^{o b s}$ is the brightness temperature observation, $t_{o b s}$ is the local time of observation, $t_{r e f}$ is an arbitrarily selected reference time, and $T_{b}^{\text {corr }}$ is the brightness temperature at the reference time.

\section{Results}

\subsection{SNO and Inter-Sensor Calibration Results}

Taking the SNO data point matching among FY-3D, MetOp-A, and NOAA-18 as an example, Figure 3a shows the spatial distribution of orbits of FY-3D and NOAA-18 
in the Northern Hemisphere on 1 January 2020. Black dots represent the SNO points that meet the matching criteria above. Figure $3 b, c$ shows the spatial distribution of SNO data points matched by all years' NOAA-18 data with FY-3D (MetOp-A) data in the Northern Hemisphere.

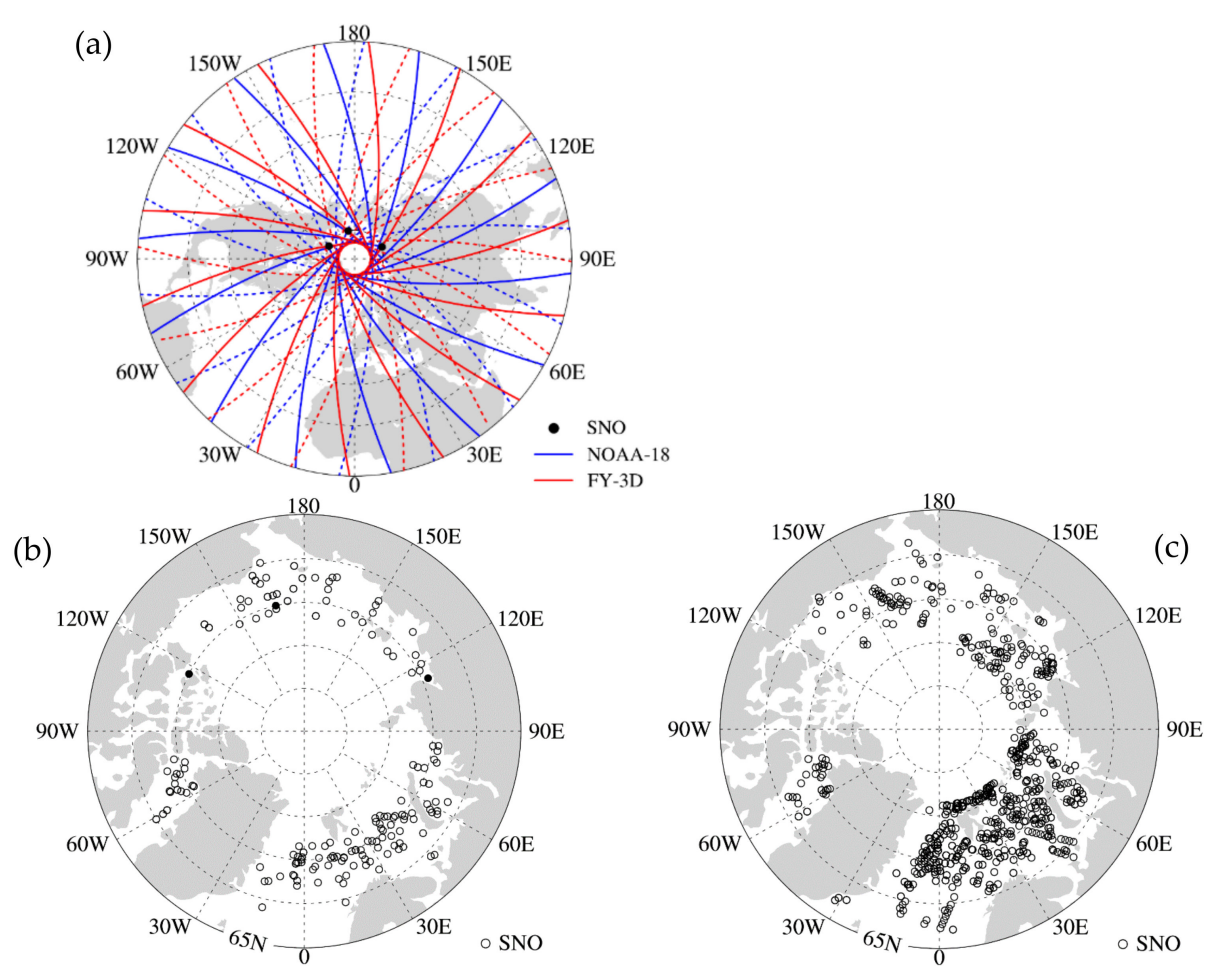

Figure 3. (a) Ascending (solid) and descending (dashed) nodes from NOAA-18 (blue curves) and FY-3D (red curves) swaths on 1 January 2020 shown under a north-polar stereographic projection, (b) all SNO points between FY-3D and NOAA-18 during January 2019 to December 2020, and (c) all SNO points between MetOp-A and NOAA-18 during January 2007 to December 2020.

Figure 4 shows scatter plots of brightness temperature observations of six paired MWTS- 2 channels, the biases, and standard deviations. It can be seen that the spreads of MWTS-2 channels 3-11 were small, and those of channels 1 and 12-13 were relatively large. The smaller the spread is, the more accurate the calculated bias is. Figure 5 shows the inter-sensor biases between NOAA-18 and all other satellites and the responding standard deviations. The standard deviations of most channels were less than $0.2 \mathrm{~K}$, except for the near-surface channels (1-3 and 15) and the stratospheric channels (13-14). The uncertainty was relatively larger for biases of channels 1-3 and 13-15 than channels 4-13. Since NOAA15 AMSU-A channels 6, 11, and 11 were all damaged before NOAA-18 was launched, their inter-sensor biases could not be calculated. Details can be seen in Tables 3 and 4 .
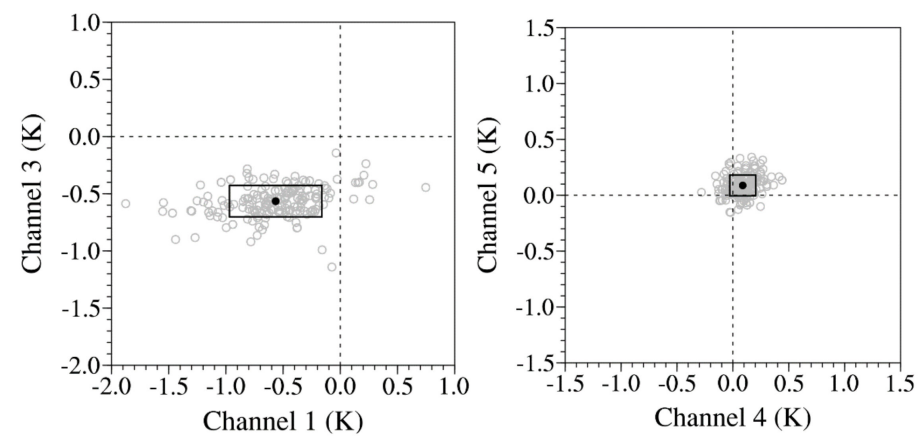

Figure 4. Cont. 

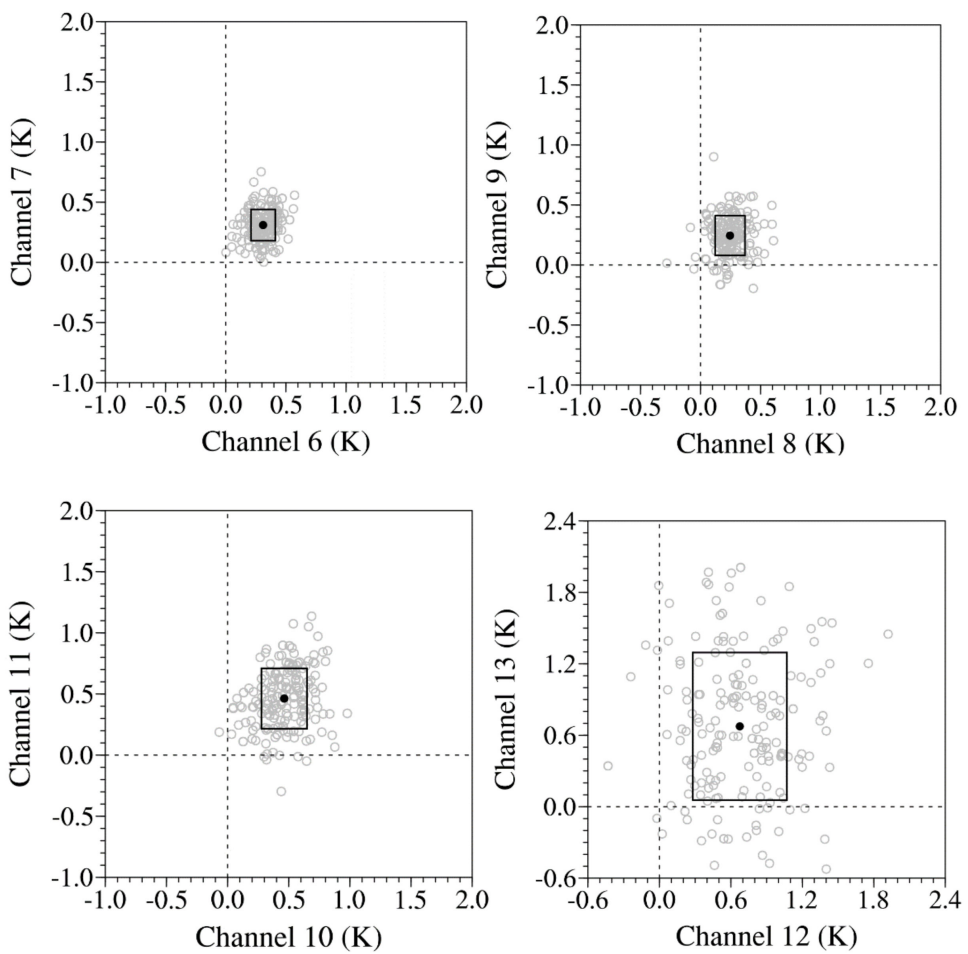

Figure 4. Scatter plots of double differences of brightness temperature observations for all FY-3D MWTS-2 channels having similar frequencies to NOAA-18 AMSU-A. The double difference bias (black solid dot) and one-standard deviation (black square) are also shown.
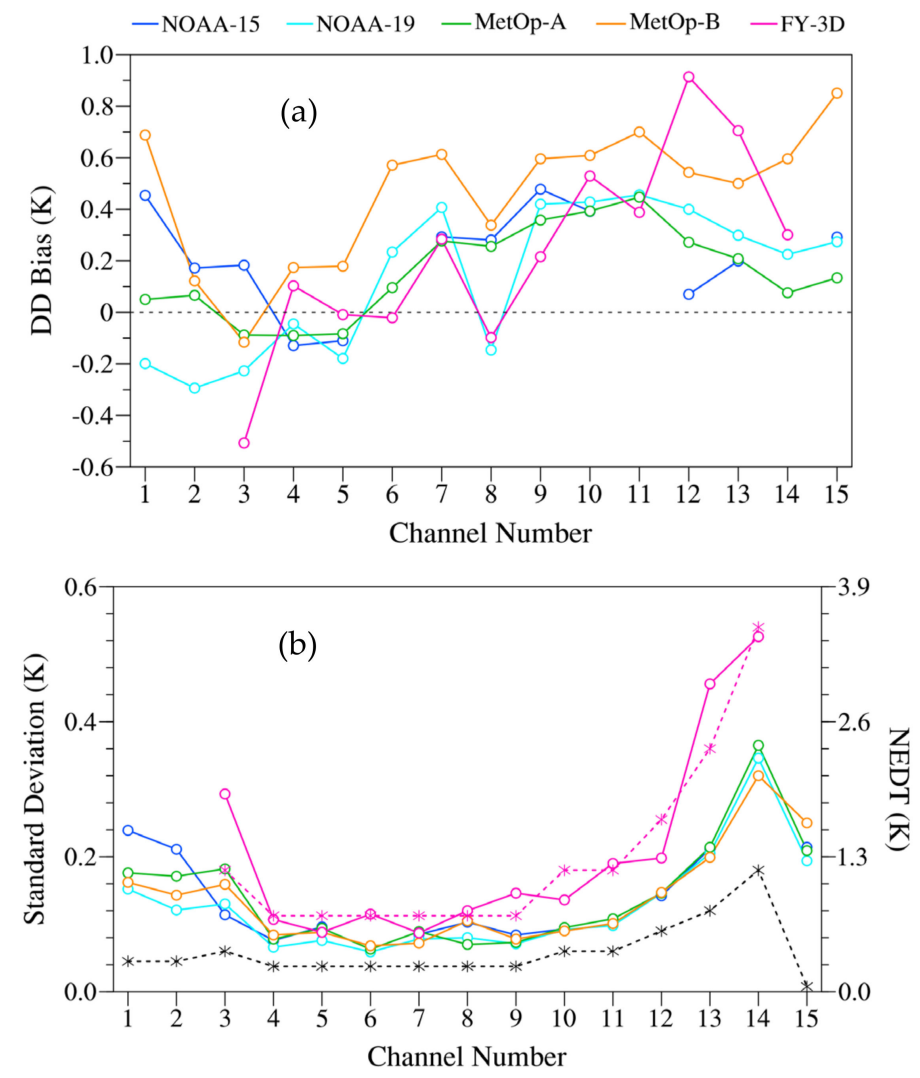

Figure 5. Variations in inter-sensor (a) double difference bias and (b) standard deviation with NEDT of AMSU-A (black dashed curve) and MWTS-2 (purple dashed curve) between NOAA-15/19, MetOp-A/B, FY-3D, and NOAA-18 for all AMSU-A channels. 
Table 3. Inter-sensor biases ( $\mu_{\text {sat }}$, unit: K) for AMSU-A channels between NOAA-15, -19, MetOp-A, $-\mathrm{B}$, and NOAA-18. $\sigma_{\text {sat }}$ (unit: $\mathrm{K}$ ) is the standard deviation. N/A stands for "not available."

\begin{tabular}{ccccccccc}
\hline & \multicolumn{2}{c}{ NOAA-15 } & \multicolumn{2}{c}{ NOAA-19 } & \multicolumn{2}{c}{ MetOp-A } & \multicolumn{2}{c}{ MetOp-B } \\
\hline Channel & $\mu_{\text {sat }}$ & $\sigma_{\text {sat }}$ & $\mu_{\text {sat }}$ & $\sigma_{\text {sat }}$ & $\mu_{\text {sat }}$ & $\sigma_{\text {sat }}$ & $\mu_{\text {sat }}$ & $\sigma_{\text {sat }}$ \\
\hline 1 & 0.454 & 0.239 & -0.199 & 0.152 & 0.050 & 0.176 & 0.688 & 0.162 \\
\hline 2 & 0.172 & 0.211 & -0.294 & 0.121 & 0.066 & 0.171 & 0.122 & 0.143 \\
\hline 3 & 0.183 & 0.114 & -0.227 & 0.130 & -0.088 & 0.182 & -0.116 & 0.159 \\
\hline 4 & -0.129 & 0.076 & -0.045 & 0.066 & -0.090 & 0.078 & 0.174 & 0.084 \\
\hline 5 & -0.110 & 0.096 & -0.179 & 0.076 & -0.083 & 0.094 & 0.179 & 0.088 \\
\hline 6 & N/A & N/A & 0.234 & 0.059 & 0.096 & 0.063 & 0.571 & 0.068 \\
\hline 7 & 0.293 & 0.085 & 0.407 & 0.078 & 0.277 & 0.089 & 0.613 & 0.072 \\
\hline 8 & 0.281 & 0.103 & -0.146 & 0.080 & 0.256 & 0.070 & 0.338 & 0.105 \\
\hline 9 & 0.478 & 0.084 & 0.420 & 0.071 & 0.358 & 0.073 & 0.596 & 0.078 \\
\hline 10 & 0.392 & 0.093 & 0.428 & 0.092 & 0.393 & 0.095 & 0.609 & 0.090 \\
\hline 11 & N/A & N/A & 0.456 & 0.098 & 0.447 & 0.108 & 0.700 & 0.101 \\
\hline 12 & 0.070 & 0.142 & 0.400 & 0.146 & 0.272 & 0.146 & 0.543 & 0.147 \\
\hline 13 & 0.199 & 0.212 & 0.299 & 0.205 & 0.208 & 0.214 & 0.500 & 0.199 \\
\hline 14 & N/A & N/A & 0.225 & 0.346 & 0.076 & 0.365 & 0.596 & 0.320 \\
\hline 15 & 0.292 & 0.214 & 0.274 & 0.194 & 0.134 & 0.209 & 0.851 & 0.250 \\
\hline
\end{tabular}

Table 4. Same as Table 3 except for FY-3D MWTS-2 and NOAA-18 AMSU-A.

\begin{tabular}{cccc}
\hline & Channel & & \\
\hline AMSU-A & MWTS-2 & $\mu_{\text {sat }}$ & $\sigma_{\text {sat }}$ \\
\hline 3 & 1 & -0.507 & 0.293 \\
\hline 4 & 3 & 0.103 & 0.107 \\
\hline 5 & 4 & -0.009 & 0.088 \\
\hline 6 & 5 & -0.021 & 0.115 \\
\hline 7 & 6 & 0.284 & 0.087 \\
\hline 8 & 7 & -0.098 & 0.120 \\
\hline 9 & 8 & 0.216 & 0.146 \\
\hline 10 & 9 & 0.529 & 0.136 \\
\hline 11 & 10 & 0.388 & 0.190 \\
\hline 12 & 11 & 0.914 & 0.198 \\
\hline 13 & 12 & 0.705 & 0.456 \\
\hline 14 & 13 & 0.301 & 0.526 \\
\hline
\end{tabular}

\subsection{Inter-Decadal Diurnal Variations over the Amazon}

Based on the method in Section 2.4, this study added FY-3D MWTS-2 data to analyze the inter-decadal diurnal variation of brightness temperature over the Amazon area; that is, the diurnal variation of brightness temperature was calculated with the data of each season of the year. Figure 6 shows the brightness temperature distribution of four seasons over the Amazon area in 2019. There was a slight difference in the diurnal variation of brightness temperature among different seasons. Since the LECT of FY-3D was 1:30 and 13:30, it made up for the gap of AMSU-A data from other satellites, which makes the fitting of diurnal variation more accurate. 
Figure 7 shows the diurnal variations of brightness temperature observations at AMSU-A channel 3 and MWTS- 2 channel 1 over the Amazon area in 2019 (dashed curves in Figure 7a), 2020 (dashed curves in Figure 7b), and 2014 (solid curves in Figure 7a). Some differences were found in the diurnal variation of brightness temperature among four seasons in different years. We therefore decided to carry out an inter-decadal diurnal correction to remove more accurately the effect of the diurnal variation on linear climate trends.
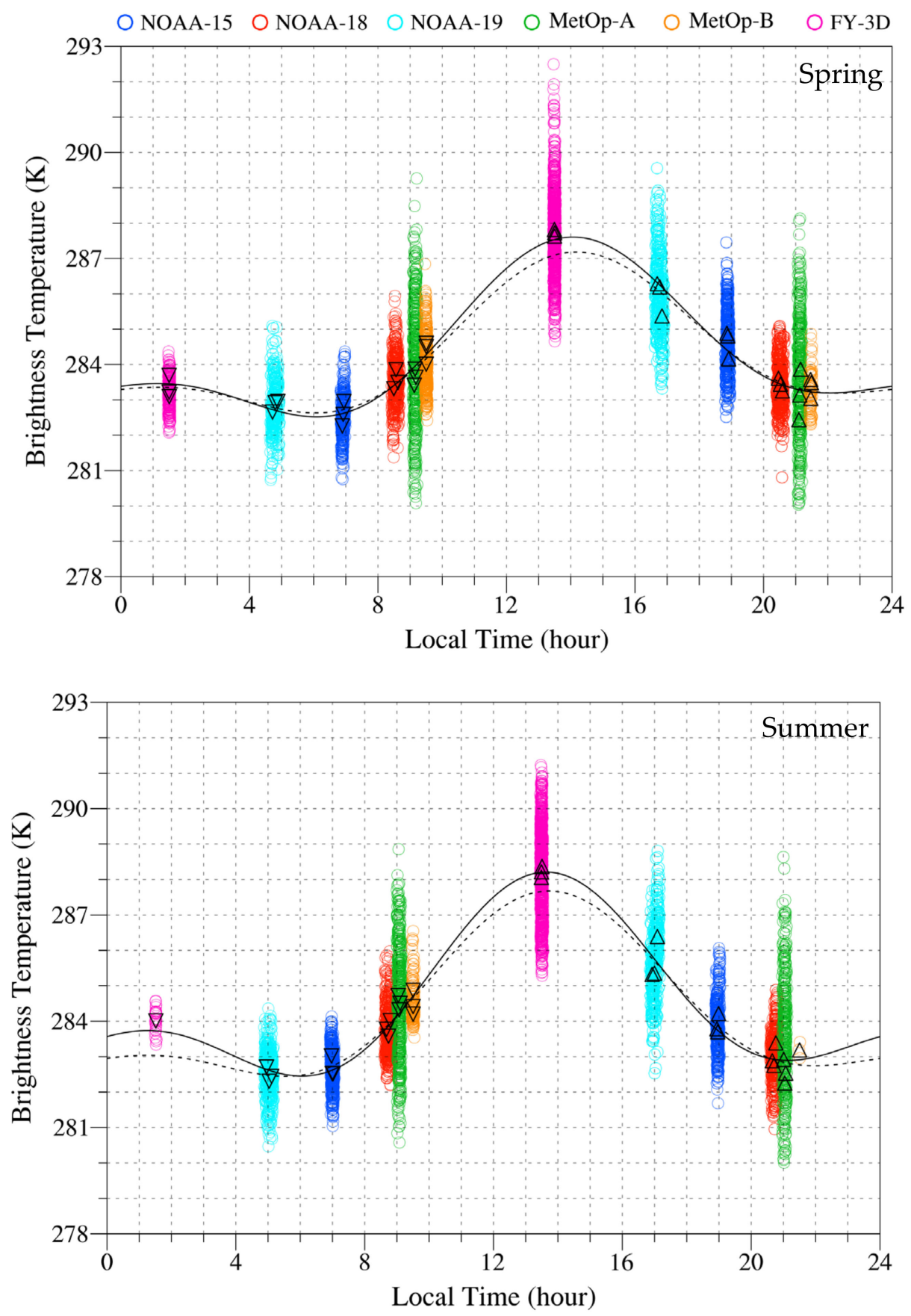

Figure 6. Cont. 

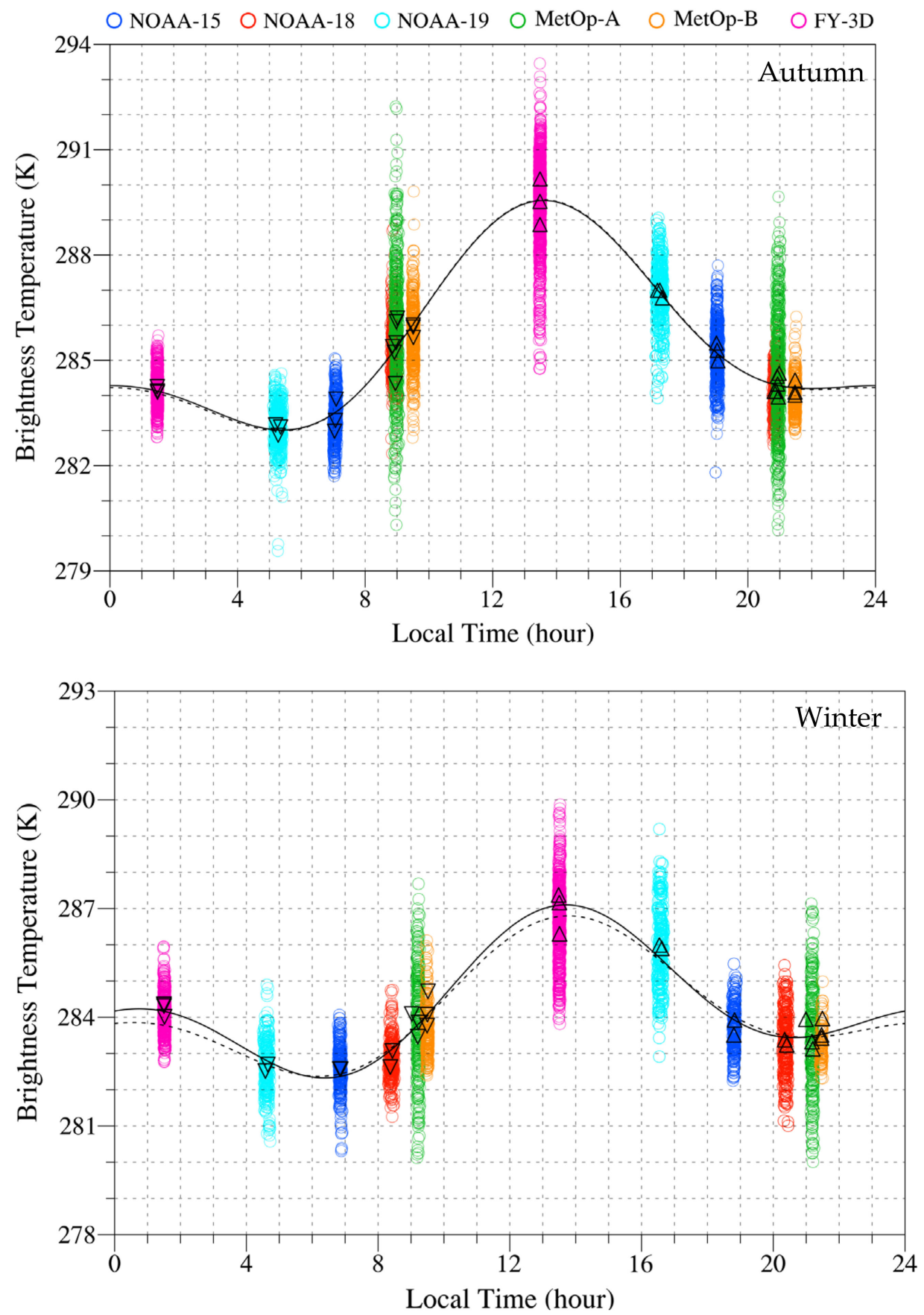

Figure 6. Brightness temperature observations (open circles) of AMSU-A channels 3 from NOAA15/18/19, MetOp-A/B, and MWTS-2 from FY-3D under "no-rain" conditions over the Amazon rainforest in spring, summer, autumn, and winter 2019. Monthly mean values on descending (downward-pointing triangles) and ascending (upward-pointing triangles) nodes were used to estimate the diurnal variation with (solid black curve) and without (dashed black curve) FY-3D data. 

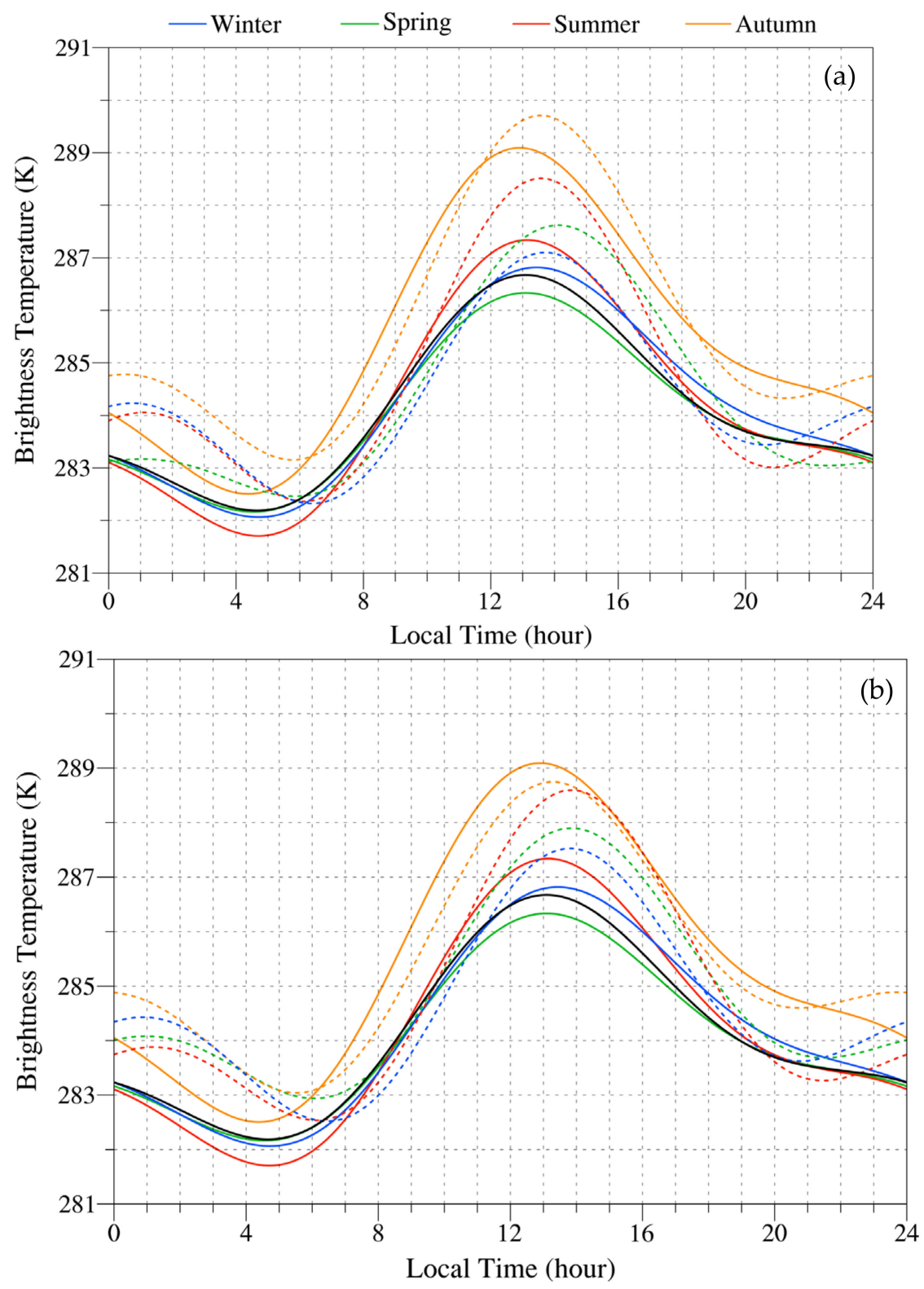

Figure 7. Diurnal variation of AMSU-A channel 3 from NOAA-15/18/19, MetOp-A/B, and FY-3D under "no-rain" conditions over the Amazon rainforest in (a) 2014 (solid curves) with 2019 (dashed curves) and (b) 2014 (solid curves) with 2020 (dashed curves). The black solid curve is the diurnal variation derived by all years' spring data.

Figure 8 shows the diurnal $\left(A_{1} \sin \theta+B_{1} \cos \theta\right)$ and semi-diurnal $\left(A_{2} \sin 2 \theta+B_{2} \cos 2 \theta\right)$ cycle of brightness temperature variation of AMSU-A channel 3 over the Amazon area from 2007 to 2020, respectively. It can be seen that the semi-diurnal cycle in Figure 8b changes greatly with years, and the addition of FY-3D MWTS-2 has a significant effect on the semi-diurnal cycle, which reduces the fitting error. Figure 9 further examines the temporal evolutions of the average value $\left(A_{0}\right)$, the diurnal amplitude $\left(\sqrt{A_{1}^{2}+B_{1}^{2}}\right)$, the semi-diurnal amplitude $\left(\sqrt{A_{2}^{2}+B_{2}^{2}}\right)$, and the root mean square error of diurnal variation. The mean brightness temperature observations in autumn were the highest. The brightness temperatures increased with time in all seasons, which corresponds to a global warming trend. The amplitudes of the diurnal variation decreased with time, and there were large variations in the summer season. The semi-diurnal amplitudes increased with time. The root mean square errors increased with time in all four seasons, with a large 
yearly fluctuation in winter season. The above results suggest that the diurnal variations of brightness temperature over the Amazon area vary yearly and seasonally, and the inter-decadal diurnal correction is required before calculating the linear climate trends of microwave observations from multiple meteorological polar-orbiting satellites.

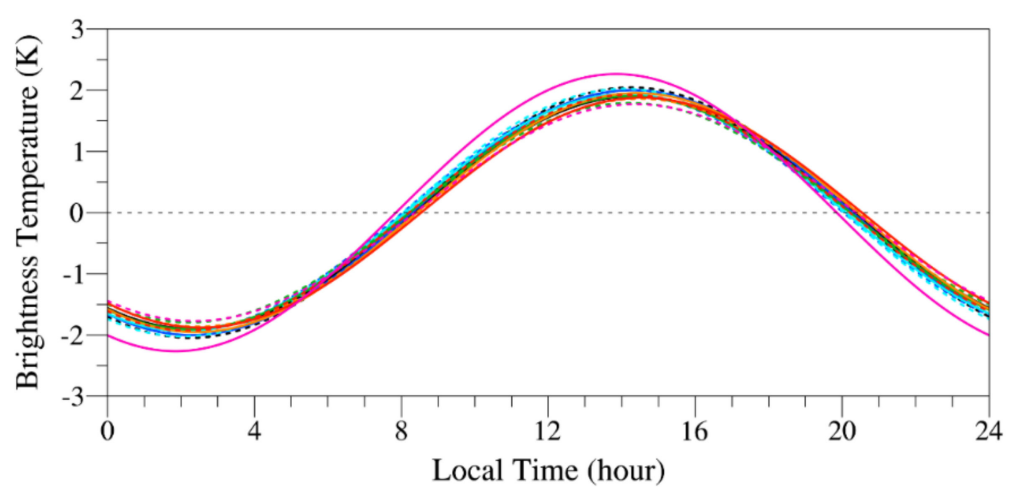

(a)

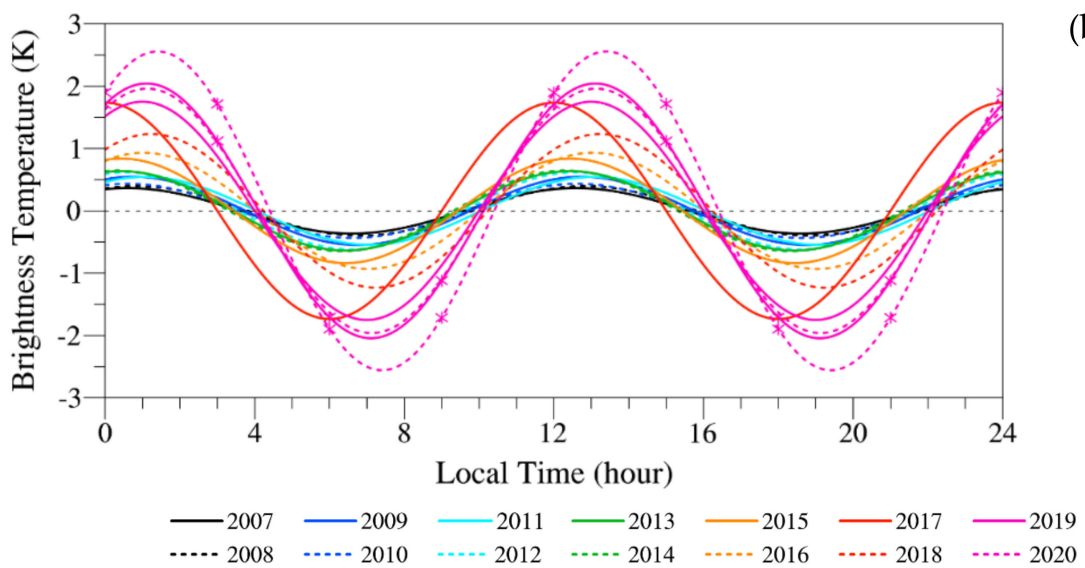

Figure 8. Decadal changes of (a) the diurnal component and (b) the semi-diurnal component of AMSU-A channel-3 brightness temperature observations in spring from 2007 to 2020 . The curves with stars mean the diurnal variations derived without FY-3D MWTS-2.

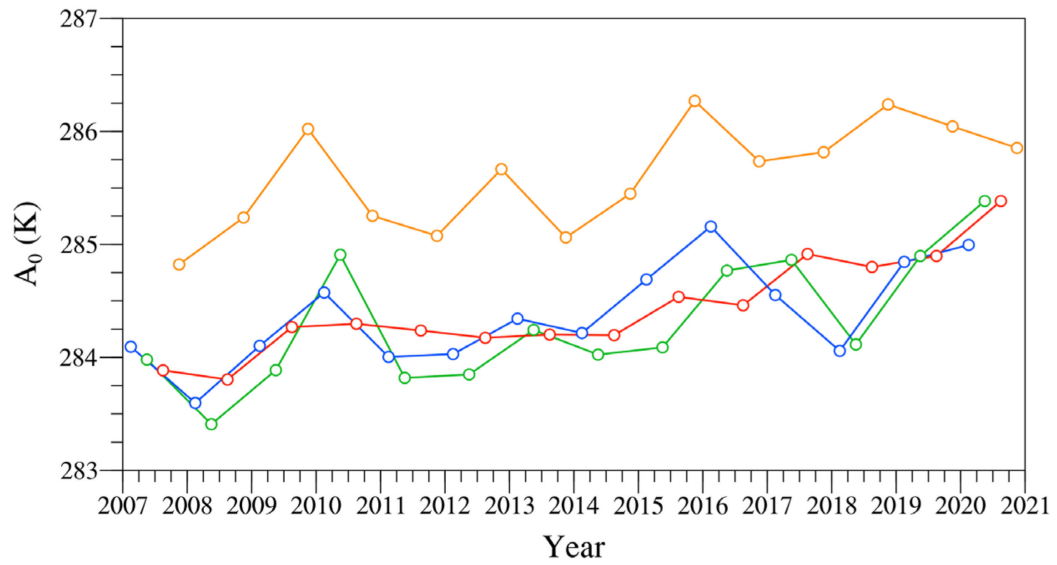

(a)

Figure 9. Cont. 


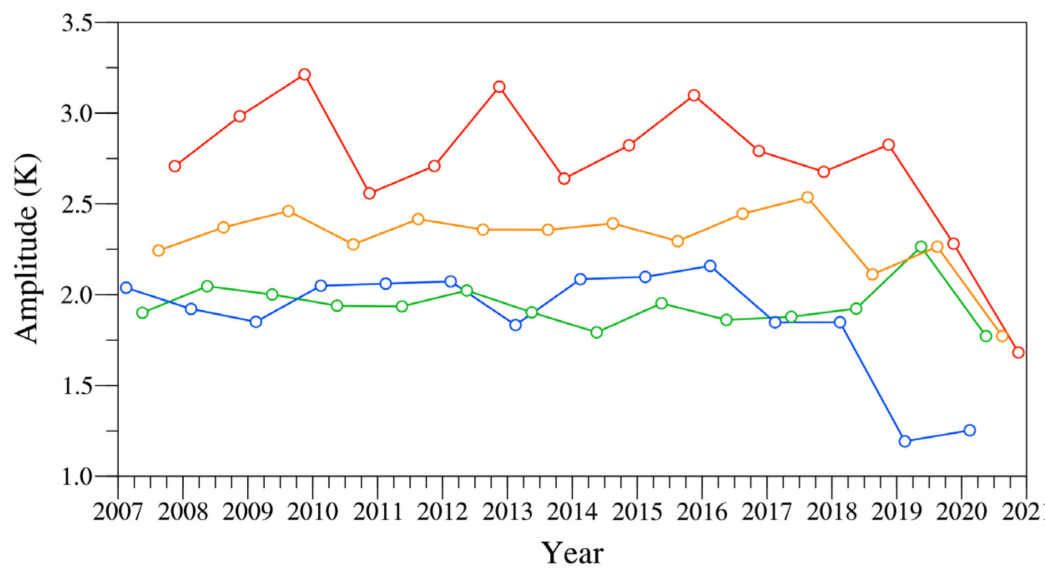

(b)

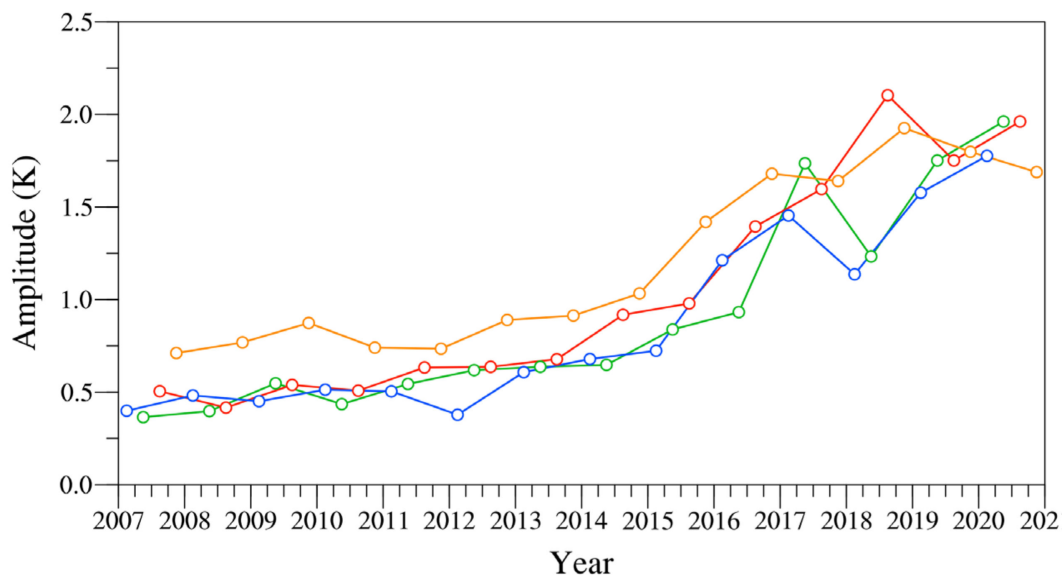

(c)

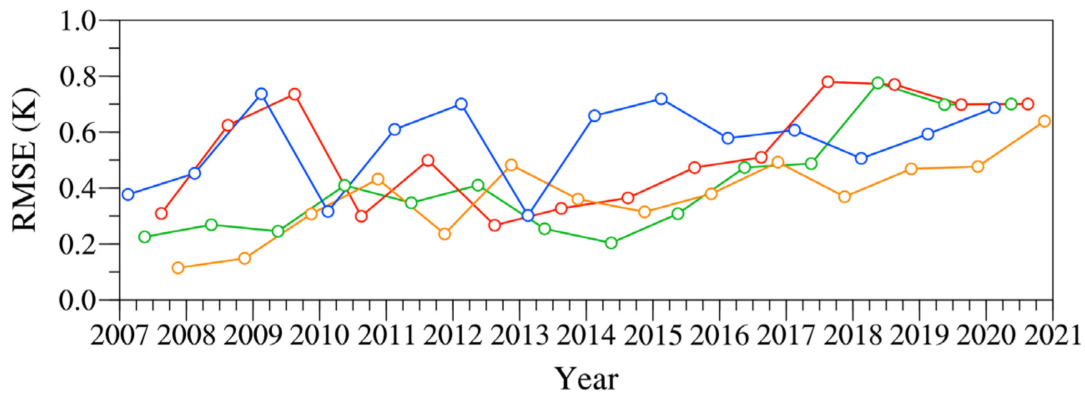

(d)

Figure 9. Decadal changes of (a) $A_{0},(\mathbf{b}) \sqrt{A_{1}^{2}+B_{1}^{2}},(\mathbf{c}) \sqrt{A_{2}^{2}+B_{2}^{2}}$, and (d) mean-square-error (RMSE) from the seasonal fit of diurnal variations for AMSU-A channel 3 in winter (blue), spring (green), summer (red), and autumn (orange) from 2007 to 2020.

\subsection{Impacts of Inter-Sensor and Diurnal Correction on Linear Climate Trends}

Having applied the inter-sensor calibration and the inter-decadal diurnal correction to AMSU-A and MWTS-2 observations from NOAA-15, -18, -18, MetOp-A, -B and FY-3D, the linear climate trend of each channel of AMSU-A could be calculated. Figure 10 shows the time series of the original data (Figure 10a), data with inter-sensor calibration (Figure 10b), and data with inter-decadal diurnal correction (Figure 10c) for AMSU-A channel 3 and MWTS-2 channel 1 over the Amazon area from 1998 to 2020, respectively. It can be seen that the data spread of the original data in Figure 10a was large, and the variations of the ascending and descending nodes data were obviously separated because of their different observing times. The inter-sensor calibration had a small impact on the data. After the inter-decadal diurnal correction, the large spread for data from the same satellite and among different satellites was significantly reduced. Figure 11 is similar to Figure 10 except for the upper-level AMSU-A channel 10 and MWTS-2 channel 9. It can be seen that 
the impact of diurnal correction for the upper-level channel in the stratosphere is not as obvious as that for the near-surface channel. That is because the solar radiation causes diurnal variation of surface temperature, and the near-surface channel is greatly affected by surface radiation.
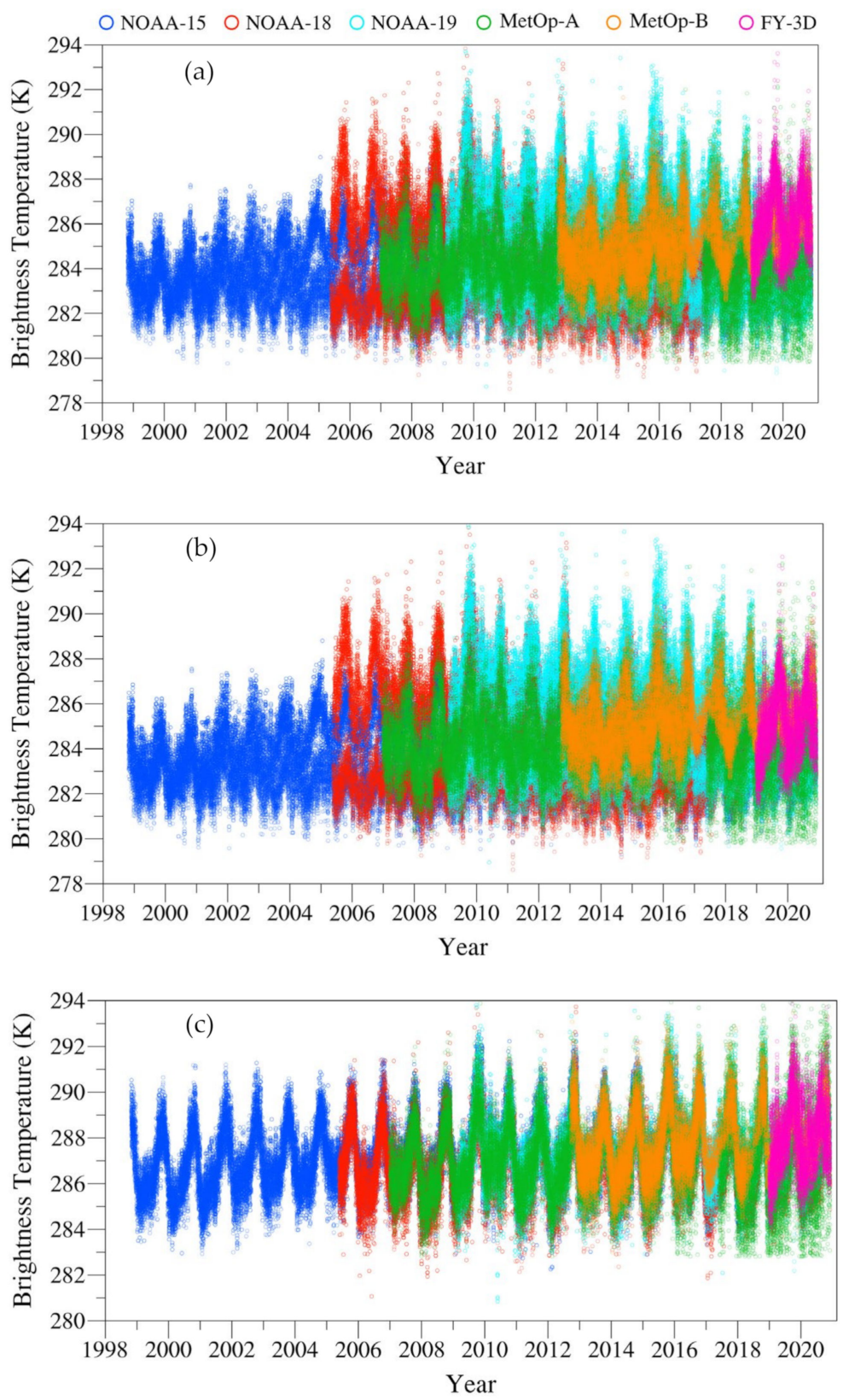

Figure 10. Time series of AMSU-A channel-3 brightness temperature observations from NOAA-15 (blue), -18 (red), -19 (cyan), MetOp-A (green), -B (orange), and FY-3d (magenta) (a) without any correction, (b) after inter-sensor bias correction, and (c) after inter-decadal diurnal correction.

In order to clearly illustrate the impact of different local times for data from the ascending and descending nodes, Figure 12a shows the local time change of observations from NOAA-15 AMSU-A observations at ascending and descending nodes over the Amazon area. Affected by solar radiation, the brightness temperatures at the ascending node were generally higher than those of the descending node. Figure $12 \mathrm{~b}$ shows the results after diurnal correction without considering the inter-decadal diurnal variation. Figure 12c shows the brightness temperature distribution after the inter-decadal diurnal correction. By comparison, it can be found that the diurnal correction considering the inter-decadal 
variation can significantly reduce the spread of data from the ascending and descending nodes. Similar results are shown in Figure 13 for NOAA-18 AMSU-A data. It shows that the inter-decadal diurnal correction can significantly improve the consistency of data from different satellites.
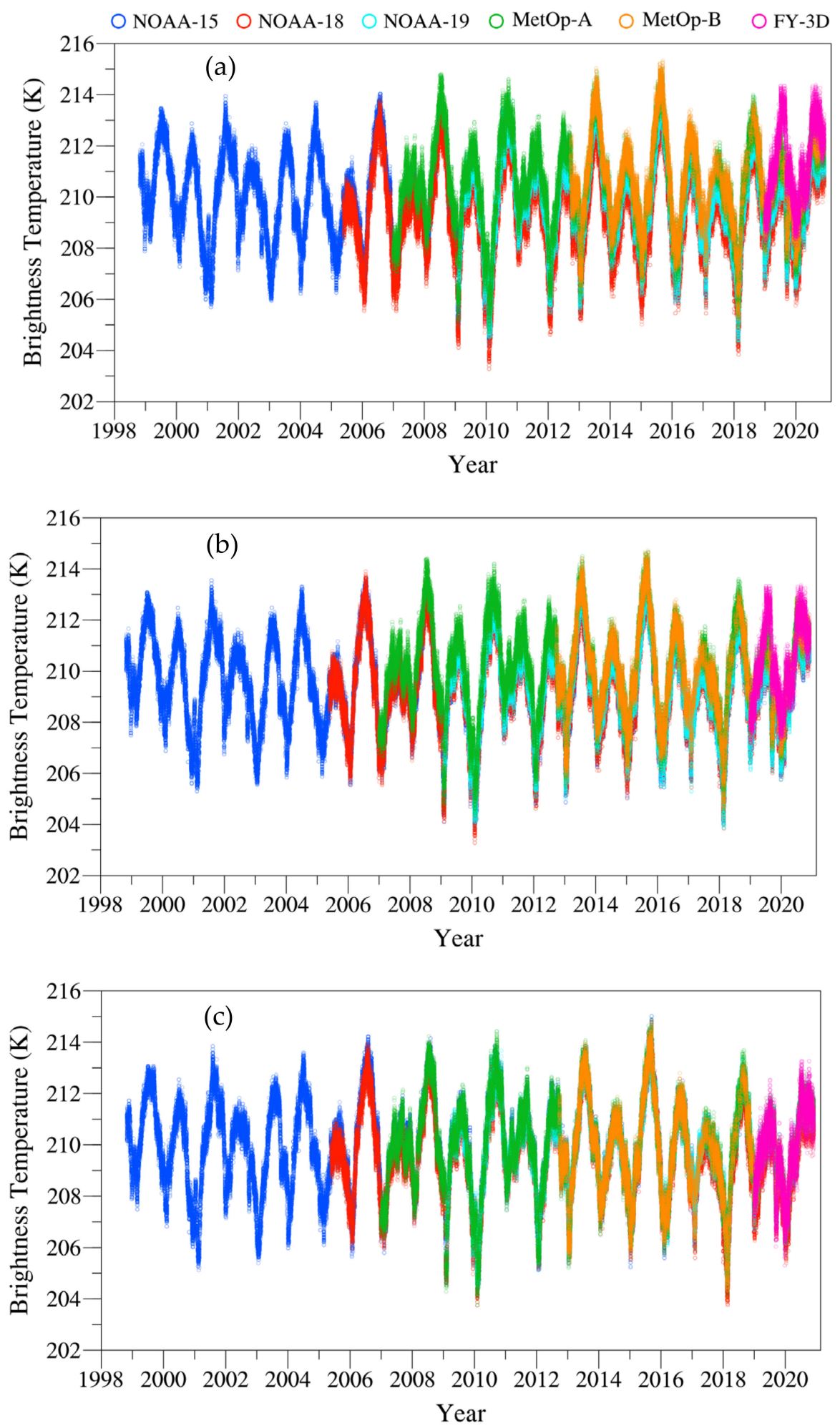

Figure 11. Same as Figure 10 except for channel 10 of (a) without any correction, (b) after inter-sensor bias correction, and (c) after inter-decadal diurnal correction. 

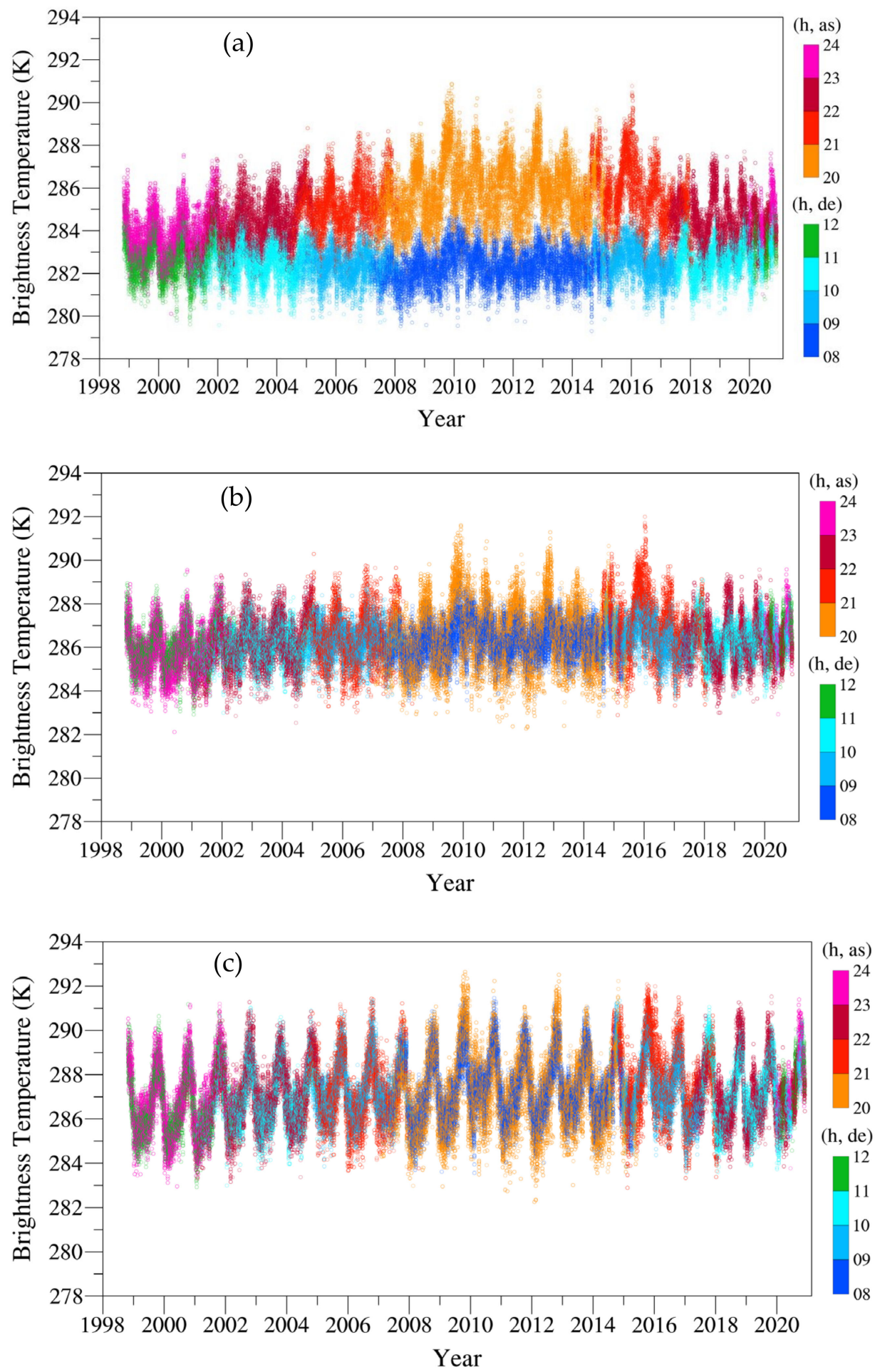

Figure 12. Time series of AMSU-A channel-3 brightness temperature observations from NOAA-15 (a) without any correction, (b) after inter-sensor bias correction, and (c) after inter-decadal diurnal correction. The observing local times are indicated in colors. 

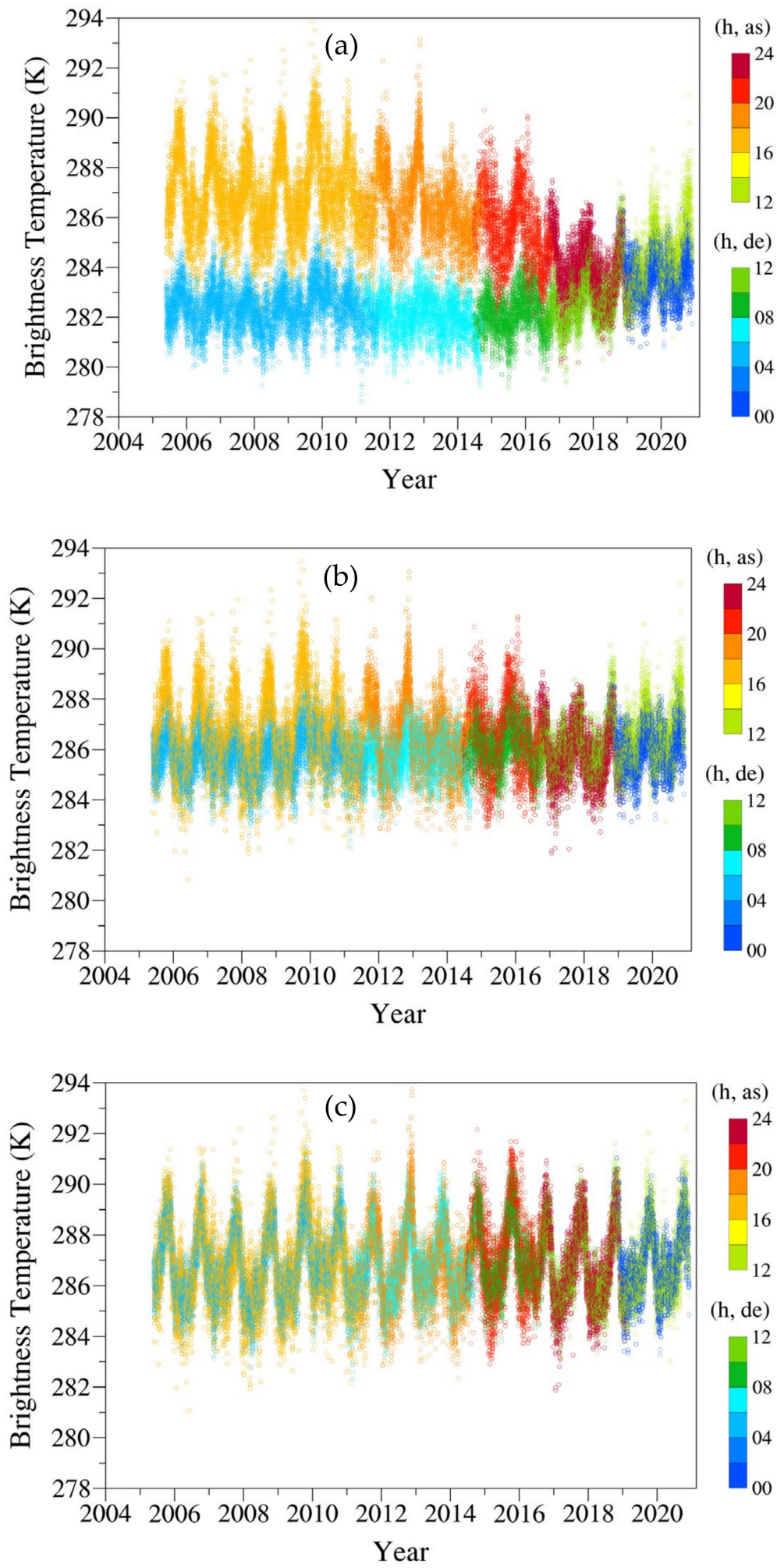

Figure 13. Same as Figure 12 except for NOAA-18 of (a) without any correction, (b) after inter-sensor bias correction, and (c) after inter-decadal diurnal correction.

Having carried out an inter-sensor bias correction and a diurnal correction, we calculated the linear trends of all AMSU-A channels over the Amazon rainforest from 1998 to 2020 (Figure 14). We observed a warming trend in the AMSU-A window and tropospheric channels (1-9 and 15) and a cooling trend in stratospheric channels (10-14). The warming (cooling) trends of channels 7-9 (10) were relatively smaller in magnitude than those of the 
other channels. For most channels, the impact of inter-decadal diurnal correction on climate trends was much greater than that of inter-sensor calibration. The warming (cooling) trends of AMSU-A channels 1-6 (14-15) were significantly reduced after the inter-decadal diurnal correction.

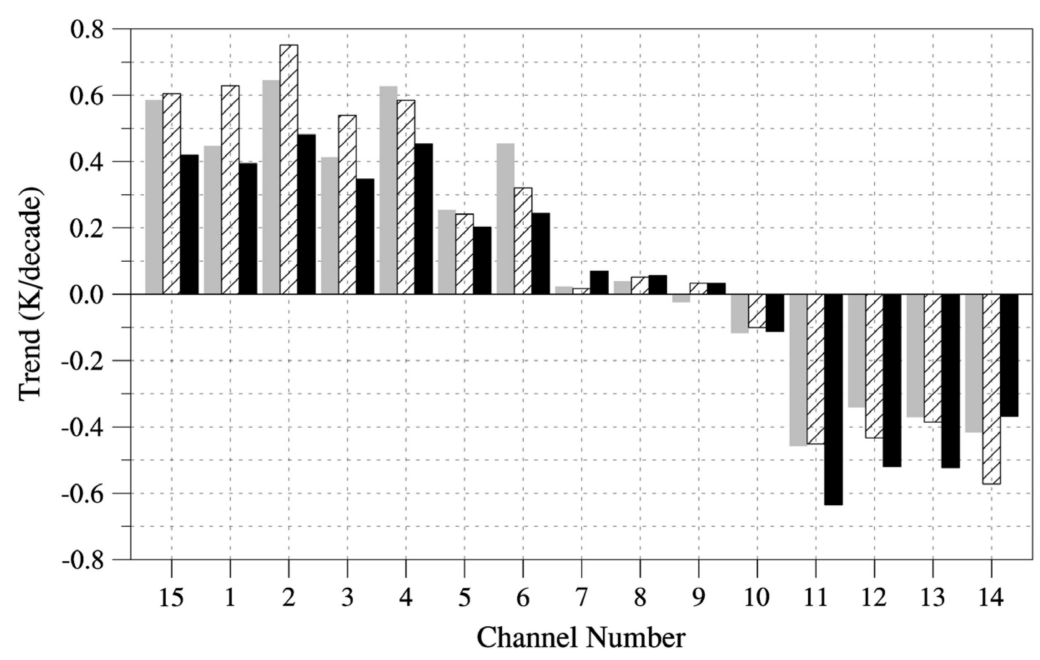

Figure 14. Decadal linear trends for all AMSU-A channels from the original data (solid grey bar) after the inter-sensor bias correction (slashed black bar) and after the inter-decadal diurnal correction (solid black bar).

\section{Discussion and Conclusions}

In this study, we combined the FY-3D MWTS-2 data with long-term AMSU-A data from NOAA-15, -18, -19 and MetOp-A, -B with inter-sensor calibration and inter-decadal diurnal correction for the first time, and we used them to calculate the linear climate trend over the Amazon area. Taking NOAA-18 AMSU-A as the reference, the SNO and DD methods were used for inter-sensor calibration. The results showed that the biases of instruments between NOAA-18 and other satellites were within $1 \mathrm{~K}$ and that the uncertainty of bias was large for near-surface and stratospheric channels, especially for MWTS-2. After that, we further developed the determination of "no-rain" with AMSU-A channels 1, 3, 8 , and 15 and applied it to MWTS-2 channels 1 and 7. We also proposed to carry out an inter-decadal diurnal correction, and the result showed that the MWTS-2 data significantly improved the fitting of diurnal variation in 2019 and 2020. By analyzing the diurnal variation of seasonal average brightness temperature over the Amazon area, we calculated the diurnal variation of brightness temperature for each year and applied the inter-decadal diurnal correction to all microwave data. After the inter-decadal diurnal correction, the brightness temperature of ascending and descending nodes from different satellites became more consistent, which helps to improve the accuracy of the calculated linear climate trend. Finally, the decadal linear trends of all AMSU-A channels from 1998 to 2020 over the Amazon were obtained, which showed a warming trend in the AMSU-A window and tropospheric channels (1-9 and 15) and a cooling trend in stratospheric channels (10-14). For most channels, the impact of inter-decadal diurnal correction on climate trends was much greater than that of inter-sensor calibration.

Author Contributions: Conceptualization, X.Z. and X.X.; methodology, X.Z.; software, X.X.; validation, X.X. and X.Z.; formal analysis, X.X.; investigation, X.X.; resources, X.Z.; data curation, X.X.; writing-original draft preparation, X.X.; writing-review and editing, X.X.; visualization, X.X.; supervision, X.Z.; project administration, X.Z.; funding acquisition, X.Z. All authors have read and agreed to the published version of the manuscript.

Funding: This research was supported by the National Key R\&D Program of China Grant 2018YFC 1507004. 
Data Availability Statement: Data sharing not applicable. No new data were created or analyzed in this study. Data sharing is not applicable to this article.

Acknowledgments: We would like to acknowledge the suggestions provided by the reviewers and the editor.

Conflicts of Interest: We declare that we have no conflicts of interest to this work. We declare that we do not have any commercial or associative interest that represents a conflict of interest in connection with the work submitted.

\section{References}

1. Jones, P.D.; Wigley, T.M.L.; Kelly, P.M. Variations in Surface Air Temperatures: Part 1. Northern Hemisphere, 1881-1980. Mon. Weather. Rev. 1982, 110, 59. [CrossRef]

2. Barnett, T.P. Long-Term Trends in Surface Temperature over the Oceans. Mon. Weather. Rev. 1984, 112, 303. [CrossRef]

3. Angell, J.K.; Korshover, J. Global temperature variations in the troposphere and stratosphere, 1958-1982. Mon. Weather. Rev. 1983, 111, 901-921. [CrossRef]

4. Andersson, E.; Hollingsworth, A.; Kelly, G.; Lönnberg, P.; Pailleux, J.; Zhang, Z. Global Observing System Experiments on Operational Statistical Retrievals of Satellite Sounding Data. Mon. Weather. Rev. 1991, 119, 1851. [CrossRef]

5. Eyre, J.R.; Kelly, G.A.; McNally, A.P.; Andersson, E.; Persson, A. Assimilation of TOVS radiance information through onedimensional variational analysis. Q. J. R. Meteorol. Soc. 1993, 119, 1427. [CrossRef]

6. Li, J.; Zou, X. Impact of FY-3A MWTS radiances on prediction in GRAPES with comparison of two quality control schemes. Front. Earth Sci. 2014, 8, 251. [CrossRef]

7. Zou, C.-Z.; Goldberg, M.D.; Cheng, Z.; Grody, N.C.; Sullivan, J.T.; Cao, C.; Tarpley, D. Recalibration of microwave sounding unit for climate studies using simultaneous nadir overpasses. J. Geophys. Res. 2006, 111, D19114. [CrossRef]

8. Wang, W.; Zou, C.-Z. AMSU-A-Only Atmospheric Temperature Data Records from the Lower Troposphere to the Top of the Stratosphere. J. Atmos. Ocean. Technol. 2014, 31, 808. [CrossRef]

9. Qin, Z.; Zou, X.; Weng, F. Comparison between linear and nonlinear trends in NOAA-15 AMSU-A brightness temperatures during 1998-2010. Clim. Dyn. 2012, 39, 1763. [CrossRef]

10. Zou, X.; Tian, X. Striping Noise Analysis and Mitigation for Microwave Temperature Sounder-2 Observations. Adv. Atmos. Sci. 2019, 36, 711. [CrossRef]

11. Niu, Z.; Zou, X.; Ray, P.S. Development and Testing of a Clear-Sky Data Selection Algorithm for FY-3C/D Microwave Temperature Sounder-2. Remote. Sens. 2020, 12, 1478. [CrossRef]

12. Goldberg, M.D.; Crosby, D.S.; Zhou, L. The Limb Adjustment of AMSU-A Observations: Methodology and Validation. J. Appl. Meteorol. 2001, 40, 70. [CrossRef]

13. Spencer, R.W.; Braswell, W.D. Atlantic Tropical Cyclone Monitoring with AMSU-A: Estimation of Maximum Sustained Wind Speeds. Mon. Weather. Rev. 2001, 129, 1518. [CrossRef]

14. Mears, C.A.; Schabel, M.C.; Wentz, F.J. A Reanalysis of the MSU Channel 2 Tropospheric Temperature Record. J. Clim. 2003, 16, 3650. [CrossRef]

15. Spencer, R.W.; Christy, J.R.; Braswell, W.D. UAH Version 6 global satellite temperature products: Methodology and results. Asia Pac. J. Atmos. Sci. 2017, 53, 121. [CrossRef]

16. Po-Chedley, S.; Thorsen, T.J.; Fu, Q. Removing Diurnal Cycle Contamination in Satellite-Derived Tropospheric Temperatures: Understanding Tropical Tropospheric Trend Discrepancies. J. Clim. 2015, 28, 2274. [CrossRef]

17. Mears, C.A.; Wentz, F.J. Sensitivity of Satellite-Derived Tropospheric Temperature Trends to the Diurnal Cycle Adjustment. J Clim. 2016, 29, 3629. [CrossRef]

18. Zou, X. Atmospheric Satellite Observations. Microwave Temperature Sounding Observations; Academic Press: Cambridge, MA, USA, 2020; pp. 97-133.

19. Mears, C.; Schabel, M.C.; Wentz, F.J.; Santer, B.D.; Govindasamy, B. Correcting the MSU middle tropospheric temperature for diurnal drifts. In Proceedings of the IEEE International Geoscience \& Remote Sensing Symposium, Toronto, ON, Canada, 24-28 June 2002.

20. Mo, T. Diurnal Variation of the AMSU-A Brightness Temperatures Over the Amazon Rainforest. IEEE Trans. Geosci. Remote Sens. 2007, 45, 958. [CrossRef]

21. Chen, H.; Zou, X.; Qin, Z. Effects of diurnal adjustment on biases and trends derived from inter-sensor calibrated AMSU-A data. Front. Earth Sci. 2018, 12, 1. [CrossRef]

22. Cao, C.; Weinreb, M.; Xu, H. Predicting Simultaneous Nadir Overpasses among Polar-Orbiting Meteorological Satellites for the Intersatellite Calibration of Radiometers. J. Atmos. Ocean. Technol. 2004, 21, 537. [CrossRef]

23. Kroodsma, R.A.; McKague, D.S.; Ruf, C.S. Inter-Calibration of Microwave Radiometers Using the Vicarious Cold Calibration Double Difference Method. IEEE J. Sel. Top. Appl. Earth Obs. Remote. Sens. 2012, 5, 1006. [CrossRef]

24. Bremen, L.V.; Ruprecht, E.; Macke, A. Errors in liquid water path retrieval arising from cloud inhomogeneities: The beam-filling effect. Meteorol. Z. 2002, 11, 13. [CrossRef] 
25. Greenwald, T.J.; Stephens, G.L.; Vonder Haar, T.H.; Jackson, D.L. A physical retrieval of cloud liquid water over the global oceans using special sensor microwave/imager (SSM/I) observations. J. Geophys. Res. 1993, 98, 18471-18488. [CrossRef]

26. Saunders, R.W.; Kriebel, K.T. An improved method for detecting clear sky and cloudy radiances from AVHRR data. Int. J. Remote. Sens. 1988, 9, 123. [CrossRef]

27. Saunders, R.; Matricardi, M.; Brunel, P. An improved fast radiative transfer model for assimilation of satellite radiance observations. Q. J. R. Meteorol. Soc. 1999, 125, 1407. [CrossRef]

28. Ferraro, R.R.; Weng, F.; Grody, N.C.; Zhao, L. Precipitation characteristics over land from the NOAA-15 AMSU sensor. Geophys. Res. Lett. 2000, 27, 2669. [CrossRef] 